\title{
Family of universal high-speed cultivators UKS
}

\author{
Galina Parkhomenko ${ }^{1}$, Sergey Kambulov ${ }^{1}$, Igor Bozhko ${ }^{1}$, Andrey Boyko ${ }^{2, *}$, Andrey \\ Reshenkin ${ }^{2}$, and Sergey Belousov ${ }^{3}$ \\ ${ }^{1}$ Agricultural research center «Donskoy», Lenina str., 14, Zernograd, 347740, Russia \\ ${ }^{2}$ Don State Technical University, Gagarin sq., 1, Rostov-on-Don, 344003, Russia \\ ${ }^{3}$ Kuban State Agrarian University named after I.T. Trubilin, Kalinina str., 13, 350000, Krasnodar, \\ Russia
}

\begin{abstract}
At present, when cultivating various agricultural crops, there is an increased load of machine-tractor units on the soil horizon, due to the use of multi-operational tillage technology. The family of universal high-speed cultivators UKS of 10-, 12- and 14-meters working width simultaneously performs the following technological operations: loosening without turning the layer with cutting and combing out weeds, as well as compacting and mulching the soil surface. UKS cultivators include the following structural elements: a frame with a hitch, a hydraulic system, a disc bar, a frame consisting of the middle and side sections and wings on the transverse bars of which there are five rows of duckfoot paws, support-running wheels, and a scraper frame with seals. In the course of field research of the developed universal high-speed cultivators, it was established that their quality indicators correspond to the agrotechnical requirements: the deviation of the processing depth from the average does not exceed $1.5 \mathrm{~cm}$; the presence of ridges on the surface of the field less than $3 \mathrm{~cm}$ high; the number of fractions less than $25 \mathrm{~mm}$ in size (crumbling) was more than $80 \%$; crop and plant residues remained on the surface of the field by at least $80 \%$.
\end{abstract}

\section{Introduction}

The modern direction of mechanization of agricultural production provides for the most complete use of the energy resources of machine and tractor units while ensuring the specified quality indicators of the technological process. This ensures the economic efficiency of using a reasonable composition of machine and tractor units. When cultivating various crops, there are multiple passes through the field of machine-tractor units associated with tillage. Multiple passes of machine-tractor units across the field lead to over consolidation of the soil in the arable and subsoil horizons. As a result, it becomes necessary to develop cost-effective tillage machines, the functioning of which ensures the implementation of a given technological process without over compaction of the arable and subsoil horizons. Soil plays a critical role in the functioning of ecosystems [1]. The availability of soil water for plant transpiration is a key concept in agronomy [2]. The main task of soil cultivation [3] is to improve the water-air regime in soils, regulate their balance, ensure the accumulation of nutrients, as well as improve the physical, chemical and biological

${ }^{*}$ Corresponding author: andreyboi@yandex.ru 
properties [4]. Soil cultivation equipment can be improved according to the parameters that characterize the geometry machines and working bodies; by modes characterizing the dynamics and energetic of the process; in terms of indicators characterizing the quality of work, depending on the physical and mechanical properties of the soil [5]. Over consolidation of the soil by agricultural machines during its cultivation has a negative effect on the growth of the root and aerial parts of plants [6], as a result of which the yield of cultivated crops decreases [7]. Over consolidation of the soil can lead to physical degradation, which, from the micromorphometric side, is a process of negative transformation of the reservoir structure, which results in a decrease in the number of agronomically valuable aggregates [8]. Degradation is characterized by a change in soil properties as a result of excessive loads on the soil, which worsen its physical condition and agrotechnical indicators of the process [9]. According to the authors [10-15], the number of passes has a more significant effect on the compaction of loamy soil than the vertical load due to the weight of the machine. Therefore, soil cultivation must be carried out with machine-tractor units that exclude multiple passes and minimal impact on the layer. The minimum impact on the seam is carried out by the working bodies of cultivators for shallow and shallow soil cultivation. When processing the soil with machine-tractor units, which include wide-cut cultivators, the number of passes through the field for performing the technological process is significantly reduced. At the same time, the productivity of the machine and tractor units will increase due to the increase in the width of the cultivator and ensure the economic efficiency of their use. An additional increase in productivity is ensured by increasing the speed of movement of machine and tractor units. Wide-range cultivators ensure the loading of the tractor, thereby the most complete use of energy resources. The scientific novelty consists in establishing the relationship between the qualitative and energy indicators of the technological process of shallow and surface tillage with the parameters and operating modes of cultivators for its implementation, taking into account the properties of the treated environment. Depending on the agrotechnical requirements, the type of technological operation and the conditions of the treated environment, various combinations of working bodies are installed on the cultivator frame. The significance of the research lies in the improvement of the technological process and design of wide-cut cultivators that provide high-quality and cost-effective shallow and shallow tillage in one pass of the machine-tractor unit. Purpose of work: to develop wide-cut high-speed cultivators that performs a given technological process with the required quality indicators in one pass.

\section{Materials and methods}

A monographic survey of the known bearing systems of working bodies for shallow and shallow soil cultivation, an analysis of their functioning in the field and theoretical studies made it possible to develop the design of a family of universal high-speed cultivators for continuous and presuming loosening with the destruction of weeds, with simultaneous soil compaction and mulching. The unified design is developed according to the method of the basic unit with a single bearing system (cultivator frame) and replaceable parts (variants of working bodies).

The research consisted in a comprehensive study of the complex system "processed environment - options for working bodies for shallow and surface tillage" as a whole in the process of real functioning.

Comparison of the results of the system functioning under changing conditions of the processed environment was carried out in order to achieve the best energy performance of the technological process when fulfilling agricultural requirements. 


\section{Research results}

The ANC "Donskoy" has developed a family of universal high-speed cultivators UKS of 10, 12- and 14-meter working width. UKS simultaneously performs the following technological operations: loosening without turning the seam with cutting and combing out weeds, compacting and mulching the soil surface. UKS consists of 1 with a hook-on device; hydraulic systems; bar of discs 2 ; frame 3 , consisting of middle, side sections and wings, on the transverse bars of which there are five rows of lancet paws; paired support wheels 5 and the frame of the combers 6 with seals 7 (Figure 1). Depending on the conditions of the processed environment, the UKS is completed with one or two rows of combers; the bar of discs can be dismantled; duckfoot shares are mounted on straight, C-shaped or S-shaped posts.

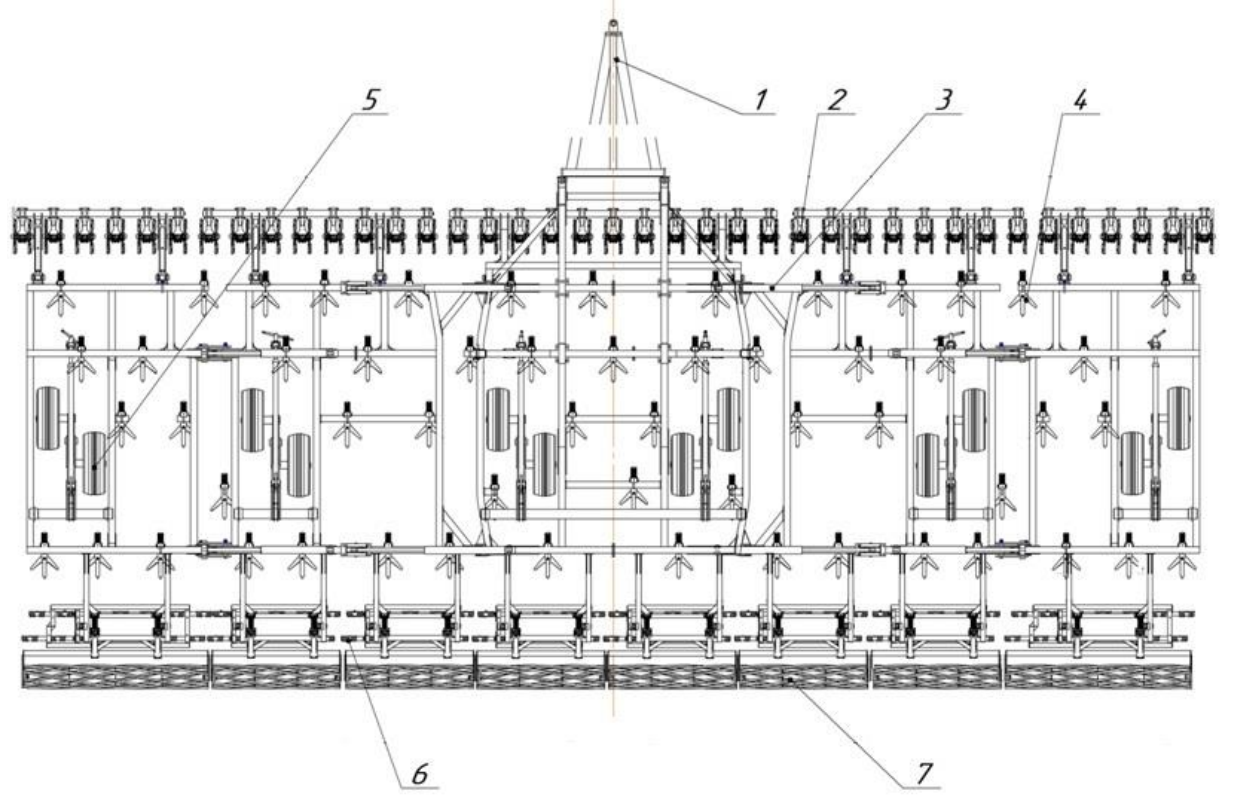

Fig. 1. UKS-14 scheme.

Where: 1 - snits; 2 - turbo disks; 3 - frame; 4 - lancet paws; 5 - support wheels; 6 - combers; 7 seals.

When the cultivator moves across the field in the working position, the discs cut the weeds and the soil layer at a predetermined depth, which enters the paw surface, crumbles, falls to the bottom of the furrow and is exposed to the comb teeth, crushing the soil fractions and combing weeds from the loosened layer to the surface and compactors mulch, level and compact the field surface.

The technical characteristics are presented in table 1.

Table 1. Technical characteristics of UKS-14.

\begin{tabular}{|l|c|}
\hline \multicolumn{1}{|c|}{ Indicator name } & The quantity \\
\hline Unit type & trailed \\
\hline Traction class of the tractor, $\mathrm{t}$ & 5 \\
\hline Working speed, $\mathrm{km} / \mathrm{h}$ & $10-12$ \\
\hline Transport speed, $\mathrm{km} / \mathrm{h}$ & Under 15 \\
\hline Capture width, $\mathrm{m}$ & 14 \\
\hline Processing depth, $\mathrm{cm}$ & $5 \ldots 12$ \\
\hline
\end{tabular}




\begin{tabular}{|l|c|}
\hline Lamp type & lancet \\
\hline Basic geometric parameters of the paw: & 72 \\
- opening angle, 0 & 23 \\
- crumbling angle, 0 & 13 \\
- ascent angle, 0 & 33 \\
- capture width, cm & 5 \\
\hline Number of rows of paws, pcs. & 56 \\
\hline Number of paws, pcs. & 80 \\
\hline Distance between paws in a row, cm & 80 \\
\hline Distance between rows of paws, cm & 25 \\
\hline Paw spacing, cm & straight. wavy \\
\hline Disc types & 42.5 \\
\hline Disc diameter, cm & 39 \\
\hline Number of paired disks & 30 \\
\hline Roller (compactor) diameter, cm & $1 ; 2$ \\
\hline Number of harrow rows (comber) & 78 \\
\hline Paw stand type & 12 \\
\hline Support-running wheels diameter, cm & 6 \\
\hline Number of support-running wheels, pcs. & 43 \\
\hline Number of paired support wheels, pcs. & 1 (ractor driver ) \\
\hline Transport clearance, cm & $9270 \times 14620 \times 1400$ \\
\hline Service staff, people & $9270 \times 4500 \times 4475$ \\
\hline Overall dimensions, mm (length $\square$ width $\square$ height) & 9700 \\
\hline - in working position & not less than 0.98 \\
\hline in transport position & \\
\hline Weight, kg & -shaped; S-shaped; straight \\
\hline Process reliability factor & \\
\hline
\end{tabular}

The frame is welded from rectangular pipes. Consists of a middle section, two side sections and two wings. Each frame section contains front, rear and side rails. The side rails of the sections and one side rails of the wings contain devices for articulation. Spring holders, brackets for mechanisms for adjusting the working depth are rigidly attached to the frame beams; pivotally - supporting wheels. On the frame, transverse beams are welded to connect the lancet paws. For greater rigidity, the front and rear beams of each section are reinforced in the form of a truss with an additional tube of a smaller section. All sections have lugs on top, with which they are connected by means of hydraulic cylinders. The middle section has removable supports for fixing the side frames in the transport position. Disc frames are hinged on the front beam of all frame sections, and on the rear, the scraper frames with seals are rigidly attached.

Paired wavy discs (turbo discs) or straight disc knives are hung on a bar, which is pivotally attached with two brackets 3 to the front bar of each frame section. Discs 1 are spring-loaded by compression spring 2 (Figure 2). The bar of the side knives is connected to the bar of the cultivator frame by means of adjustable rods, which allows changing the depth of the discs. 


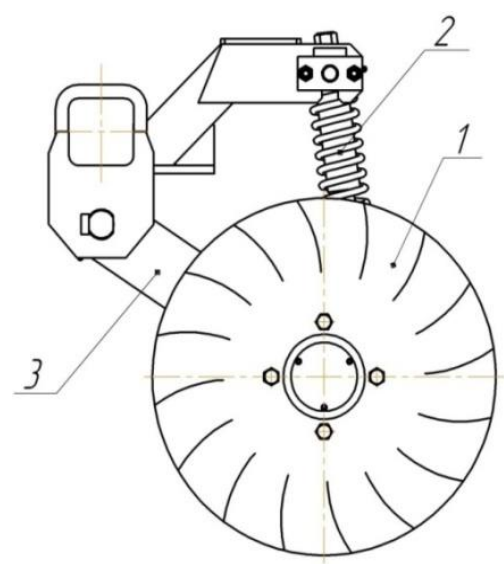

Fig. 2. Turbo disks. Where: 1 - disk; 2 - spring; 3 - bracket.

A lancet paw with a straight leg is fixed in a holder, the connection of which with the frame is carried out through two springs, the free ends of which are rigidly fixed by means of two pads and bolts. The lancet share with a C-shaped leg is equipped with a compression spring.

The frame of the scrubber with seals consists of longitudinal and transverse bars, on which the frames of the scraper holders and the roller frames are attached. The frame of the scraper 1 holders is attached to the frame of the 6 scrubber with seals (Figure 3). Racks 7 of the rotary seal 2 are attached to the lowering frame 4 of the seal, which is connected to the frame 6 of the combers with seals. The seal 2 is equipped with reducers, which are bolted to the frame 4 of the seal. Each seal 2 is spring-loaded with two compression springs 5 relative to the frame 6 of the combers with seals.
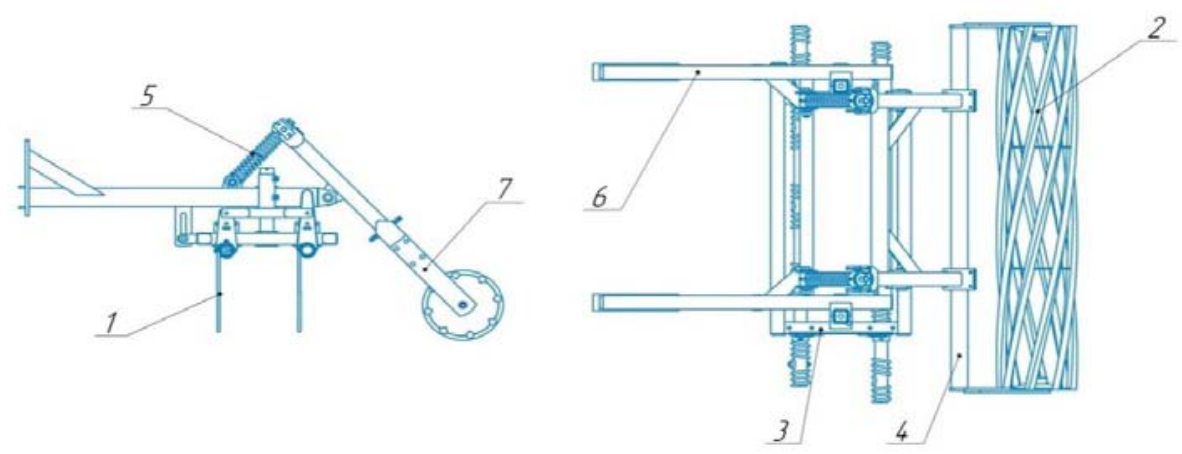

Fig. 3. Scrubber and compactor. Where: 1 - scrubber; 2 - sealant; 3 - frame of the scraper holders; 4 seal frame; 5 - seal spring; 6 - the frame of the combers with seals; 7 - rack.

The supporting wheels are designed to support the frame, ensure the stability of the combined unit in operation and in the transport position, serve to raise and lower the working bodies, as well as to set the preset tillage depth. Support-running wheels are paired, contain a balance bar on which a two-armed lever is mounted on the bearing, connected to a hydraulic cylinder fixed to the rack of the depth adjustment mechanism.

The triangular shape is welded from rectangular pipes. In the front part, the snitch has a towing device for connecting to a tractor, and on the opposite side it has lugs for a hinge connection with the frame of the unit. A hydraulic cylinder 4 and a screw mechanism connected to the rocker are mounted on top of the cage (Figure 4). 


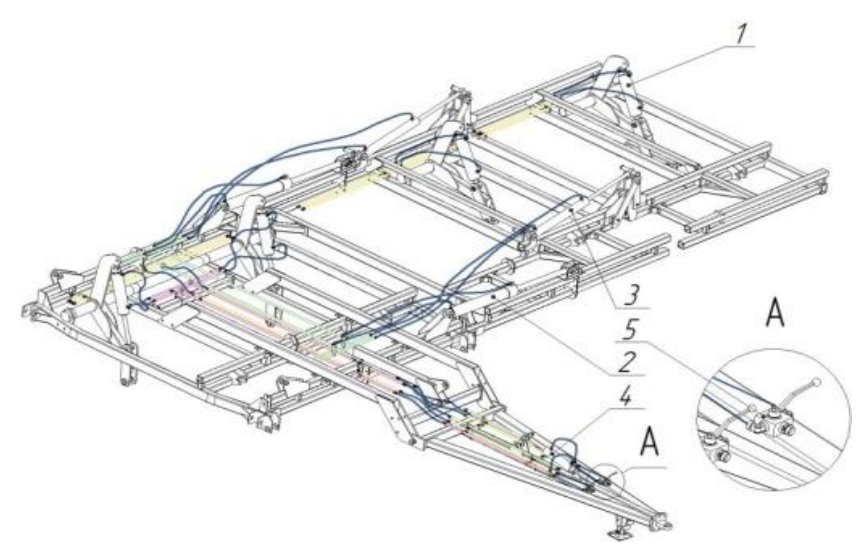

Fig. 4. Cultivator hydraulic diagram. Where: 1 - carriage hydraulic cylinder; 2, 3 - hydraulic cylinders of wings and frame sections; 4 - hydraulic cylinder of the snare; 5 - three-way valve.

Such a lowering device ensures the connection of the cultivator to the tractor both to a hydraulic hitch and to a stationary hitch. The hydraulic system consists of metal hydraulic lines, including distribution columns, tees and connecting unions. Hydraulic lines, hydraulic cylinders and distribution valves are connected by flexible pipelines (high pressure hoses). Metal hydraulic lines are attached to the cultivator frame with brackets and clamps. On hydraulic cylinders 2,3 , retarding valves are installed to prevent the working bodies from hitting the ground when lowering the wings and frame sections. Three-way valves 5 are designed to distribute flows in two directions: to the hydraulic cylinders of the central carriage and wing carriages 1 , and to block the flow to the central carriage in the transport position.

The cultivator is transferred to the transport position by raising the side sections 2 and wings 3 of the frame, folding it in a vertical position and then fixing it (Figure 5). The middle section 1 remains in the same position.

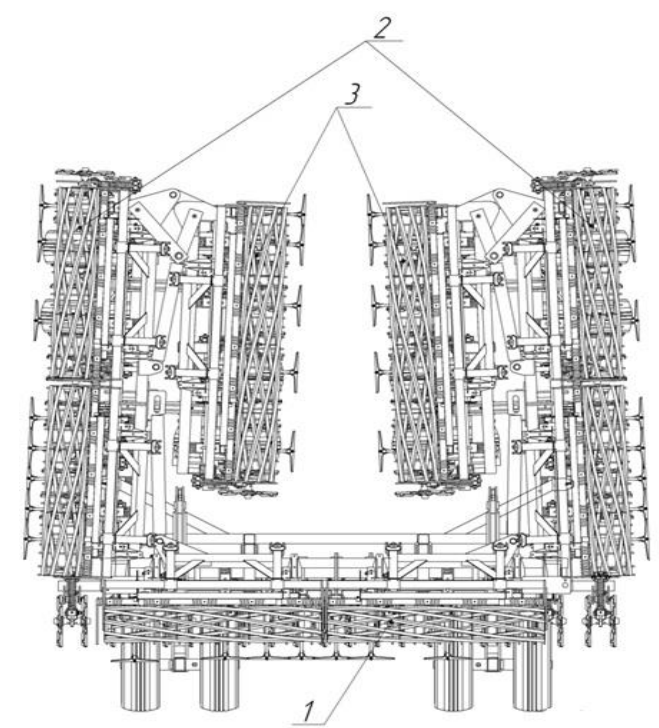

Fig. 5. Cultivator in transport position. Where: 1 - central section; 2 - side sections; 3 - wings.

Field studies of the developed universal high-speed cultivators have established that their quality indicators correspond to agrotechnical requirements for all configuration options: the 
deviation of the processing depth from the average does not exceed $1.5 \mathrm{~cm}$; the presence of ridges on the surface of the field less than $3 \mathrm{~cm}$ high; the number of fractions less than 25 $\mathrm{mm}$ in size (crumbling) was more than $80 \%$; crop and plant residues remained on the surface of the field by at least $80 \%$.

The family of high-speed universal cultivators meets environmental requirements: the number of erosion-hazardous particles less than $1 \mathrm{~mm}$ in size in the upper soil layer $(0-5 \mathrm{~cm})$ is reduced in comparison with their content before the passage of the working bodies; plant and crop residues are preserved; the minimum impact on the soil is ensured due to the combination and execution of several technological operations in one pass and a decrease in the number of passes due to an increase in the working width.

\section{Conclusion}

Soil cultivation must be carried out with machine-tractor units, which exclude multiple passes and minimal impact on the layer by the working bodies of cultivators. When cultivating the soil with wide-grip cultivators, the number of passes through the field for performing the technological process is significantly reduced, productivity increases due to an increase in the working width and an increase in travel speed.

At ANC "Donskoy", high-speed cultivators have been developed that perform a given technological process with the required quality indicators in one pass: deviation of the working depth from the average to $1.5 \mathrm{~cm}$; the height of the ridges is less than $3 \mathrm{~cm}$; more than $80 \%$ of fractions less than $25 \mathrm{~mm}$ in size; preservation of crop residues $80 \%$; the amount of erosive particles is reduced.

\section{References}

1. K. Adhikari, A.E. Hartemink, Geoderma 262, 101-111 (2016) doi: 10.1016/j.geoderma.2015.08.009

2. V. Couvreur, J. Vanderborght, X. Draye, M. Javaux, Water Resources Research 50(11), 8891-8906 (2014) doi: 10.1002/2014WR015608

3. G.G. Parkhomenko, S.G. Parkhomenko, Intelligent machine technologies and equipment for the implementation of the State Program for the Development of Agriculture: collection of scientific reports of the International Scientific and Technical Conference VIM, 210-214 (2015)

4. Zs. Sándor, M. Tállai, I. Kincses et al., DRC Sustainable Future 1(1), 14-20 (2020) doi: 10.37281/DRCSF/1.1.3

5. P. Cârdei, A. Meca, G. Kostadinov, INMATEH 37(2) (2012)

6. Adnan Noor Shah, Mohsin Tanveer, Babar Shahzad et al., Environ Sci Pollut Res. (2017) doi: 10.1007/s11356-017-8421-y

7. G.G. Parkhomenko, S.G. Parkhomenko, Grain storage and processing 2(210), 20-24 (2017)

8. G.G. Parkhomenko, S.G. Parkhomenko, Technical service of machines 2(135), 40-46 (2019)

9. G.J. Burton, D.S. Shend, C. Cambell, Géotechnique Letters 4(2), 88-93 (2014) doi: 10.1680/geolett.14.00003

10. J.M. Konrad, M. Lebeau, Canadian Geotechnical Journal 52(12), 2067-2076 (2015) doi: 10.1139/cgj-2014-0300

11. V.R. Akuraju, D. Ryu, B. George, Y. Ryu, K. Dassanayake, Agric. For. Meteorol. 232, 489-499 (2017) doi: 10.1016/j.agrformet.2016.10.007 
12. Y. Fang, Y.Du, J. Wang, A. Wu, S. Qiao, B. Xu, S. Zhang, K.H.M. Siddique, Y. Chen, Front. Plant Sci. (2017) doi: 10.3389/fpls.2017.00672

13. B. Ehdaie, A.P. Layne, J.G. Waines, 186, 219-232 (2012) doi: 10.1007/s10681-0110585-9

14. D. Helmana, I.M. Lenskya, D.J. Bonfilb, Early prediction of wheat grain yield production from root-zone soil water content at heading using Crop RS-Met 232, 11-23 (2019) doi: 10.1016/j.fcr.2018.12.003

15. O. Miller, D. Helman, T. Svoray, E. Morin, Field Crops Research 231 (2018) doi: 10.1016/j.fcr.2018.11.011 